\title{
Leadership in the Tug of War Between What Is Desired, What Is Possible, and What Is Allowed - Knowledge and Ideas Gained from 25 Years of Senior Management Experience in Radiology
}

\section{Führung im Spannungsfeld von Wollen, Können und Dürfen - Erkenntnisse aus 25 Jahren Leitungserfahrung in der Radiologie}

Author

Affiliation
H. P. Busch

Department for Radiology, Neuroradiology, Sonography und Nuclear Medicine, Krankenhaus der Barmherzigen Brüder, Trier
Key words

management

- leadership

process enhancement

received $\quad 21.8 .2014$

accepted 25.9.2014

Bibliography

DOI http://dx.doi.org/

10.1055/s-0034-1385436

Published online: 2014

Fortschr Röntgenstr 2014; 186:

1075-1081 @ Georg Thieme

Verlag KG Stuttgart · New York .

ISSN 1438-9029

\section{Correspondence}

Prof. Dr. Hans-Peter Busch

Abteilung für Radiologie,

Neuroradiologie, Sonographie und Nuklearmedizin,

Krankenhaus der Barmherzigen Brüder

Nordallee 1

54292 Trier

Germany

Tel.: ++ 49/6 51/2082840

Fax: ++49/6 51/2082842

h-p.busch@bk-trier.de

\section{Abstract \\ $\nabla$}

A decisive factor in the difference between the success and failure of the development of practices and hospitals is the quality and number of suitable staff members, together with their motivation to devote their skills to the particular organization. Senior management is not required or paid to paint dramatic pictures of current and future problems, but to achieve success within given framework conditions (e.g. health funding, local circumstances, suitability of senior staff). Success must be measurable and verifiable within the dimensions of medical quality, service quality and economic viability - but also regarding staff loyalty and staff recruitment. This paper is intended to encourage critical reflection on structures and roles in the organization of hospitals and practices on the basis of knowledge and ideas gained from 25 years of senior management experience. The content of this article will apply only in part or not at all for a number of successful hospitals and practices. The aim of this paper is to increase that proportion.

Key Points:

- This "culture of continuous change" represents a challenge for the thinking and actions of senior management.

- Readying the minds of employees for change is a main task of senior management.

- Leadership is more than just "good management" of the daily routine.

- Clarify your desire, ability and permission before beginning a task!

Citation Format:

- Busch HP. Leadership in the Tug of War Between What Is Desired, What Is Possible, and What Is Allowed - Knowledge and Ideas Gained from 25 Years of Senior Management Experience in Radiology. Fortschr Röntgenstr 2014; 186: 1075-1081

\section{Zusammenfassung \\ $\nabla$}

Eine erfolgreiche Unternehmensentwicklung von Praxen und Krankenhäusern wird entscheidend bestimmt durch die Qualität und Quantität geeigneter Mitarbeiter und deren Motivation, ihre Fähigkeiten dem Unternehmen zur Verfügung zu stellen. Führungskräfte werden für den Erfolg in bestehenden Rahmenbedingungen (Finanzierung des Gesundheitssystems, lokale Bedingungen, Eignung der Vorgesetzten) benötigt und bezahlt. Erfolg muss dabei messbar in den Dimensionen medizinische Qualität, Servicequalität und Wirtschaftlichkeit - aber auch bei den Kriterien Mitarbeiterbindung und Mitarbeitergewinnung - nachgewiesen werden. Der vorliegende Beitrag soll der kritischen Reflexion von Strukturen und Rollen in der Organisation Krankenhaus und Praxis aus 25 Jahren Leitungserfahrung in der Radiologie dienen. Für einige erfolgreiche Krankenhäuser und Praxen wird der Inhalt dieses Beitrags nur teilweise oder gar nicht zutreffen. Dann ist es Ziel des Beitrags, deren Anzahl zu steigern.

A decisive factor in the successful development of practices and hospitals is the quality and number of suitable employees together with their motivation to devote their skills to the organization. This is particularly true for senior management who determine the future and shape the work environment with their ideas and by example. Senior management bear a personal, non-delegable responsibility for the successful development of the organization. They must have a clear vision and objectives and systematically pursue these with empathy, enthusiasm, and the trust of their staff. 


\section{Framework conditions for senior management} $\nabla$

Senior management are not required or paid to paint dramatic pictures of current and future problems, but to achieve success within given framework conditions (e.g. health funding, local circumstances, suitability of senior staff). Success must be measurable and verifiable within the dimensions of medical quality, service quality and economic viability - but also regarding staff loyalty and staff recruitment.

Medical quality, service quality, and economic viability Continuous optimization of treatment processes within the dimensions of medical quality, service quality, and economic viability is required in the current healthcare system.

This "culture of continuous change" represents a challenge for the thinking and actions of senior management.

According to the professional code of conduct, physicians are responsible for medical quality on the basis of therapeutic freedom. Thus, physicians want to, should, and must also offer patients treatment forms that are not profitable. However, framework conditions require daily compromises on the part of physicians, nurses, and administrators. The question is unfortunately not: "Which financial resources do I need for optimum treatment quality?" but rather "how can I provide the highest possible quality with the available allocated or generated resources?" In reality physicians must earn their therapeutic freedom. Ensuring the survival of practices and hospitals requires total costs to be significantly below revenues.

But where are the efficiency reserves that allow this broad therapeutic freedom? The answer is in part: Optimization and restructuring of processes and structures and advanced training of people. This strategy results in advantages in competition but not all problems and shortcomings in the healthcare system are compensated.

\section{Efficiency reserves in competition on the basis of} performance and cost competition

In "competition on the basis of performance and cost competition with quality guarantee", efficiency reserves can be found in an increase in the efficiency of individual services (e.g. cost-effective examination with equally high quality), and in the case of hospitals also in effectiveness (e.g. determining medical necessity of individual services), i.e., the quality of cross-departmental total treatment processes from admission to discharge. Optimization should not focus on working more or faster in the existing structures and processes but on working differently in new structures and processes. In this case not only completed individual services (number of services) but also service quality and avoidance of non-medically necessary individual services, i.e., process quality, are at the center of the motivation and reward system. To date, even if associated with an advantage for patients and for the profitability of hospitals in the flatrate system, the active avoidance of unnecessary individual services results in a loss of revenues in practices and in job cuts in hospitals - and all employees know this. The goal is therefore: To increase the number of services (e.g. by recommending non-medically necessary follow-ups), not to increase service quality and process quality in an attempt to secure jobs - a false incentive.

\section{Employees are at the center of the organization}

The existence of a practice or a hospital can be jeopardized by insufficient medical quality and service quality or insufficient profitability as well as by a lack of sufficiently qualified personnel. Today it is common to see large numbers of unsuitable applicants for open positions and it is also a common occurrence for these applicants to be hired by hospitals/practices "in need" - thus potentially triggering a "death spiral" for these organizations. Finding and retaining suitable personnel is one of the most important duties of senior management - even in the case of unfavorable framework conditions.

In their fight for survival, organizations have to compete for qualified and motivated employees.

The framework conditions of the "DRG world" require a change among senior management. Many trusted processes and the status quo of individual optimization efforts that were useful in the past must be given up in the future in favor of the "optimization of total processes" ( $\bullet$ Fig. 1).

Requirement of the DRG world:

Think, act and optimize in a cross-departmental manner in total processes from admission to discharge

(medical quality, service quality, and economic viability).

Employees are at the heart of a successful development on the basis of their professional qualifications and their desire, ability, and permission to optimize processes even with changed tasks, roles, structures and responsibilities and thus to contribute to a quality offensive necessary for the survival of a hospital.

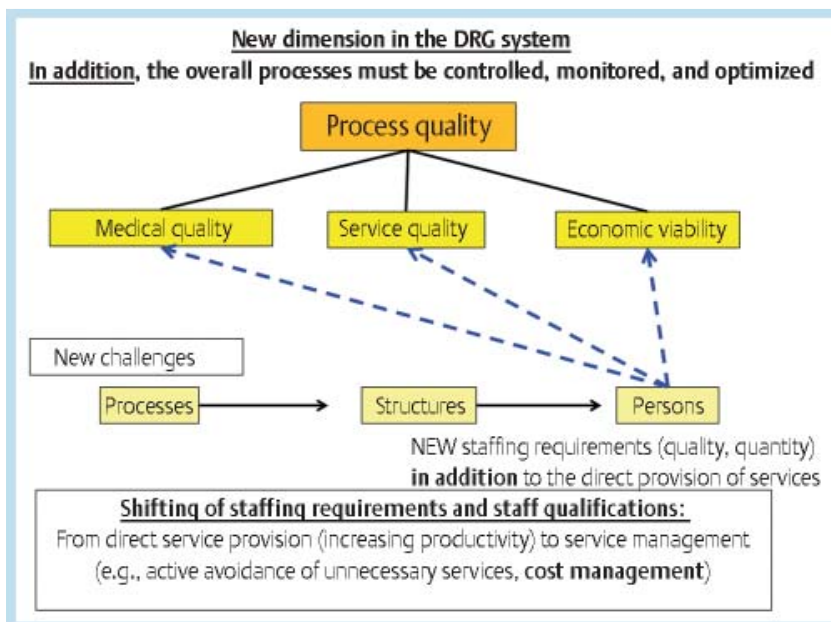

Fig. 1 Process quality - a new dimension of optimization. 
An important aspect in the competition for good employees is that optimized structures and processes (medical quality, service quality, economic viability) must additionally clearly include improved work conditions (quality of life) - a new challenge.

Good employees (e.g., qualified specialists) can pick and choose positions. These "market conditions" force hospitals to actively attract employees with outstanding working and living conditions (work-life balance), i. e., to largely meet expectations - a new challenge for professional personnel management as well as for hospital management, senior management, and all employees.

In the case of poor working conditions, the best employees with good options unfortunately are the first to go. Good employees typically attract good employees and bad employees....

Patients and applicants directly perceive the quality of the working atmosphere and make a decision based on this to stay or go when they have suitable alternatives.

It is relatively easy to ensure a good working environment in good times but is a challenge for senior management in bad times. The attitude "impossible under such bad framework conditions" is inadequate and unprofessional in the competitive situation. Managers who can act as "motivators" and "optimists" to create a positive working environment and climate of change are sought. Only senior management who do not waste time complaining, accept these challenges and thus the framework conditions, and include qualified and motivated employees in the strategic further development in a positive internal climate of change will be successful. This is not a hope for the future but a requirement for ensuring a future.

\section{Senior management requirement profile}

$\nabla$

Senior management in a hospital must first recognize the necessity for changes in processes and structures, create a climate of change, prepare senior management and employees for these changes in the framework of professional change management via suitable personnel development (social and management competence), and even shape the future. This requires systematic development of one's own methodological competence, social competence, and management competence ( $\diamond$ Table 1 ). Frequently lacking competencies are as follows:

Methodological: insufficient experience with systematic and lasting change management,

Strategic: recording and reduction of complexity,

Social: the ability to always look at oneself first for possibilities to improve a situation.

Brainstorming about new forms of organization of a hospital without limiting framework conditions confronts senior management whose development has always been accompanied by objections, restrictive framework conditions, and skeptics with impossible challenges. New creativity in lateral thinkers must often first be reawakened.
Table 1 Requirement profile for medical employees (social and management competencies).

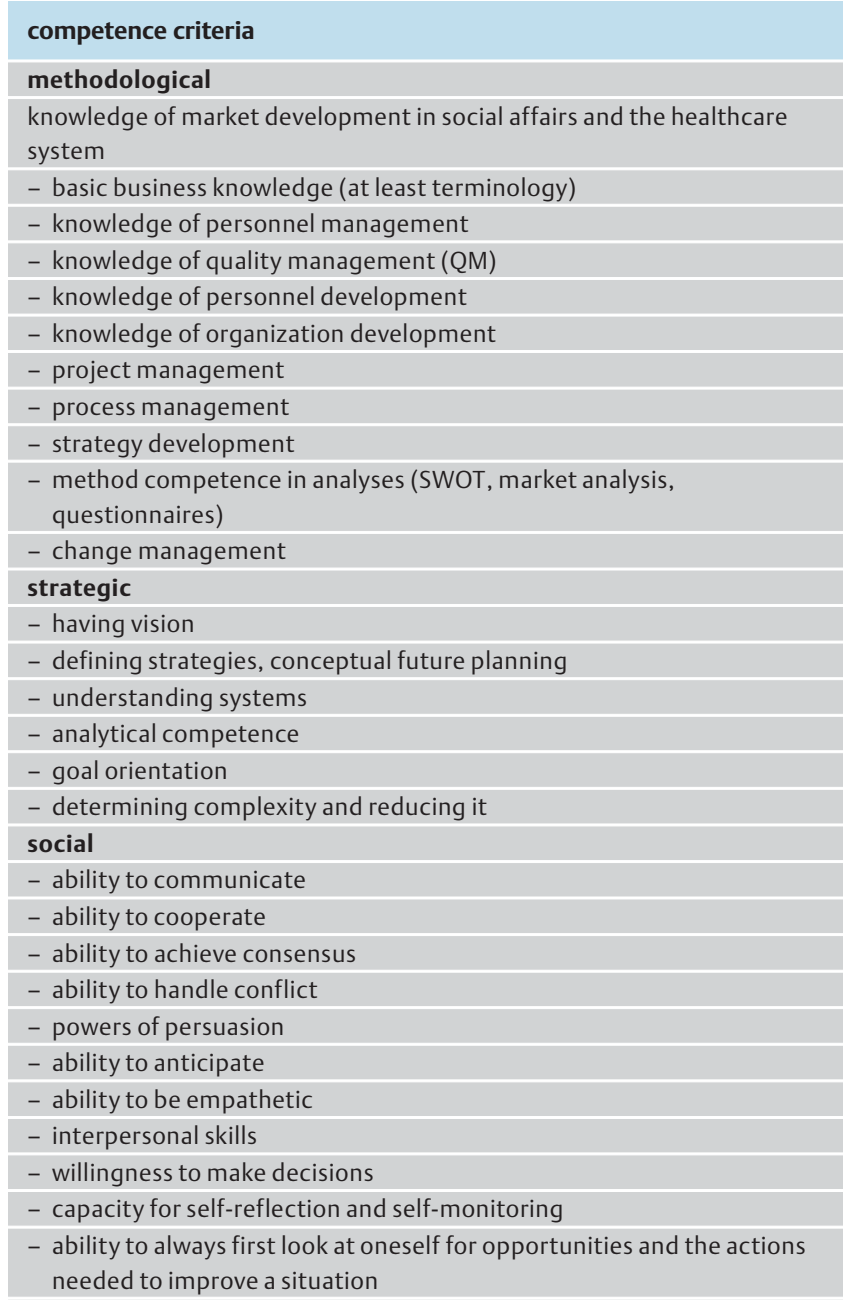

From: H. P.Busch: Managementhandbuch für Radiologen, Thieme Verlag 2008)

\section{Readying the minds of employees for change is a main task of senior management.}

The implementation of promising results and strategies often fails due to poor presentation of information. Systematic information and communication management is an underestimated task. Knowledge is power. Therefore, knowledge is often functionalized. Systematic transparency is difficult. Transparent information management requires competence, time, and IT solutions.

Sende nicht nur eine Information mit Sendeprotokoll aus, sondern überzeuge dich auch davon, ob Sie verstanden (und umgesetzt) wurde. Das ist eine neue aufwendigere Strategie! Ich habe doch Herrn XX gesagt. ....., ist keine Lösung!

In particular the daily tug of war between medicine and economy makes the change in the requirement profile of senior management clear. Medical senior management may be seen by group and hospital management as a valued medical expert and business partner with substantial advi- 
sory skills and organizational competence - this position must grow and be developed - or may function only in the role as top physician without management ambitions - a familiar position. In the latter case management duties must be outsourced to the administration. Nonetheless, medical experts without management ambitions must also be successfully utilized in a suitable environment for patients and the hospital - a challenge for structures and people.

Senior management must prepare organizations for the world of tomorrow with a focus on the quality of the results of comprehensive total processes. This far exceeds successful management of the daily routine and places new demands on the skills of management personnel. Senior management must have vision and be measured by their ability to realize this vision. As the leader you must make sure that your team is willing to follow you into and help your conquer new and unknown territory. You need the trust of your employees to be able to be a pioneer among the competition because of the lack of established models of success. Once these exist, the opportunity for gaining a head start is over.

\section{Decisive task of the future: Personnel development}

$\nabla$

In the case of senior executives (head physician, medical director, business director, director of nursing), systematic personal development of social and management competence is usually concluded with hiring. This is unfortunate because, for example, young head physicians have often had management training and young business directors have increasingly had medical training that would be useful to further develop. Yet head physicians are unfortunately typically overwhelmed by the clinical routine already on their second day of work and quickly forget their management skills. Expectations placed on new head physicians are almost exclusively of a medical nature. Good management is simply assumed and is only questioned in the case of clearly undesirable developments. Individual senior physicians are then sent for leadership development and may come back from a particularly good workshop with new ideas. These ideas then tend to be seen by the "boss" and junior employees as a threat to the status quo and familiar processes or are at least met with a lack of understanding. In this case the desire and ability of the employee is denied the necessary permission. Everything is soon forgotten and processes and ways of thinking remain the same. The result of personnel development without standards and sustainability is frustration and demotivation for the future of all those involved.

In the daily routine senior management serve as a model for personnel development. Therefore, supervisors eventually have the employees that they selected and created. ("The apple doesn't fall far from the tree"). However, personnel development is not just top down but also bottom up. Employees must strive to convince senior staff of their own skills and ideas and to establish personal win-win alliances. The desire, hope, expectation, and request must be presented at the right time and with the right words. In the event of failure, the time and presentation may have been wrong. The sensitive parameters of success, money, and power must be taken into consideration - such is the "old" world.

\section{Why are skilled personnel often unsuitable as managers? \\ $\nabla$}

In daily professional life it must be asked why highly qualified physicians, nurses and administrators are often unsuitable for managing organizations or organizational units but are nonetheless promoted to or recommended for this role as a reward for good work. After a while, senior management and/or senior staff determine that the new position cannot be successfully executed with the desired quality, quality of life, and motivation. The reasons for this are often that the requirements were not sufficiently known prior to assuming of the position and the own skills and traits were not properly assessed. For example, there is a big difference between a successful surgery on a patient and managing a large surgical center, between serving as a specialist in the "protected" environment of a hospital and managing a practice in competition with commercial enterprises, and between successful work in an accounting department and managing a modern center for personnel management (human resources department) at a hospital or a collaborative practice. These positions require different personal skills, knowledge, and experience.

Leadership is more than just "good management" of the daily routine.

Not the position but successful daily actions determine success ("Leadership is action not position" (McGannhon)). An excellent senior physician will not automatically become a good head physician and an outstanding administrator will not automatically make a good business director.

Employees are often insufficiently prepared for management positions. In the tug of war between desire, ability, and permission, only insufficient development of social and management competence occurred after or in conjunction with excellent development of professional competence. The techniques can be learned to a certain degree, but the powers of persuasion and empathy necessary for managers are largely rooted in basic personal nature.

There is often a lack of critical reflection on the part of the person being promoted prior to assuming a management position. It is important to ask: Do I want and am I able to assume this management position? Am I aware of the consequences for me, my family, and the organization? One's own definition of the role often does not coincide with the requirement profile. A physician must ask himself: Do I want to assume the role of successful manager in addition to or instead of my role as successful physician? Can I act as an effective and empathetic conductor for my team? A conductor is not the best soloist but the best team leader and is thus responsible for his own performance as well as the results of the organization and team. Greater responsibility for results is usually associated with new demands, problems, and more effort. Some of these additional emotional and time resources must come at the expense of one's private life. 
According to the "Peter Principle" (Laurence J. Peter): "In time, every post tends to be occupied by an employee who is incompetent to carry out its duties." "Work is accomplished by those employees who have not yet reached their level of incompetence."

He concludes that one might be better served by avoiding the corporate ladder.

For senior management and organizations, a critical analysis of the status quo often reveals that a "painful ending" is better than "never-ending pain" - ideally through selfawareness. This is often delayed too long (with coaching attempts) to ultimately still be unavoidable.

"People are less capable of change than we think.

Do not waste your time trying to add something that nature left out. Try to bring out what is already there. That is hard enough."

M. Buckingham: Erfolgreiches Führen gegen alle Regeln (Campus Verlag 2002)

There are examples in every organization of managers promoted beyond the scope of their ability - this is unfortunate. However, there are also examples of employees refusing a promotion to a leadership position for reasons regarding quality of life, work-life balance, and generation Y. In this case the focus is on work as a means of earning money, one's own private needs, and family. This standpoint ("I don't want to climb the corporate ladder") should (must) be accepted and not be associated with a loss of image. The organization has a right to expect employees to provide their knowledge and skills without restriction to their own company during standard work hours - anything beyond that is desirable but should not be demanded. In the case of employees in a hospital, motivation to achieve maximum performance (essential for the existence of a hospital) is a particular challenge for senior management.

\section{Why are attempts to successfully develop a n organization often unsuccessful?}

Whoever has often encountered unprepared and uncomprehending participants on all levels from head physician to assistant physician in workshops and workgroups for optimizing structures and processes ("that will just keep me from my actual work") can name several reasons for this:

1. Managers cannot be convinced of the necessity to change "proven" processes and the status quo. From their standpoint, the world in their environment/on their island is still fine (e.g. all positions are filled - tolerable ratio between workload and compensation, sufficient number of patients and private patients). Strategies and change concepts are then presented by senior management who doubt the probability of success. The defenders of the status quo, skeptics, and pessimists assume control!

2. New requirements ("think and optimize in terms of total processes" - increase efficiency and effectiveness of services) require new processes, structures, and ways of thinking. However, hospital management, practice man- agement, and head physicians want to use old formulas to solve these new problems ("that always worked in the past"). The old formula is: To perform more individual services in the old known structures and processes with the same quality using existing equipment and facilities but with fewer personnel. These efforts typically end in failure and frustration. The old structures have already been pushed to the limits.

3. In the case of management staff, an escape to the personal area of expertise ("safe ground: doing what you know - that is the reason I became a physician/nurse/administrator") is often seen as a result of an aversion to or fear of strategic further development of processes, structures, and persons. Changing process and structural organization in a hospital or practice is always associated with unrest, skepticism, and resistance and who wants to take that upon themselves.

4. There is no systematic and sustained development of social and leadership competence for existing and potential senior management. "Management workshops" organized by the human resources department with speakers from outside the organization are not followed by any lasting change strategy (monitoring, systematic refreshing) and performance monitoring. Isolated further development of senior management without a parallel change of the existing processes and structures (e.g. of the responsibility structures and responsibility hierarchy) is pointless. In this case the acquired ability and desire lack the necessary permission. It is often unclear who is responsible for the development of senior management. Who is personally responsible for the success of this development of social and leadership competence in the organization as a whole?

5. There is no professional systematic change management on the operational and strategic level. There is a lack of a sufficient number of suitable structures with qualified employees for this purpose. Change management should not be an "additional" duty after a strenuous workday but rather a main responsibility of qualified and specialized additional personnel. There is often a lack of systematic monitoring of development and results (failures among management are without consequence). The plan-docheck-act (PDCA) cycle is only used in management seminars. Without this professionalism, the result is a lack of sustainability - after a brief time everything is forgotten.

6. Although the medium and long-term goals of a hospital are continually discussed among management, they are not known to other employees even though they are generally stated in memos, at informational meetings, and in the employee newsletter - lack of interest. (Lack of feedback regarding the quality of information management).

7. In the world of defenders of the status quo and skeptics, there is a lack of courage for clear specifications and decisions with consequences - the preference is to continue to manage existing processes and systems (possibly better).

8. "Saviors" should be external management consultants. They must replace missing competencies in an unfamiliar and unprepared environment. Typically one who does not possess the competence to introduce and implement changes does not possess the competence (processes, structures, people) for systematic monitoring and thus 
sustainability. He doesn't want to have to personally speak unpleasant truths.

9. Persons must adapt to the necessary (new) process and structures (selected accordingly). However, the processes and structures (and thus the patients) are often adapted to suit the available people.

A successful optimization strategy sequence is: structure and develop processes first, followed by structures, and then people.

In hospitals and collaborative practices there is not only competition in performance and cost competition with quality guarantee but also competition for change in the search for optimal processes and structures.

("It is not the large who will replace the small but rather the fast who will surpass the slow" (Prof. Dr. W. von Eiff)).

After a long learning curve based on failed attempts by the old senior management without a change of processes, structures, and persons, new managers are hired, everything that has been learned is discussed, and the cycle begins again. New senior management who want and are expected to do things differently and better are sought and found. However, after two changes of 180 degrees, you're back where you started.

Examples of this are:

- The introduction of clinical pathways (no sustainability)

- The introduction of new interdisciplinary centers having sole responsibility for optimizing total processes in a cross-departmental manner (new name in old administrative structures)

- Certifications (names without consequence)

- Systematic multi-project management that is transparent for all employees (quickly forgotten after a workshop)

- Internal cost allocation (a brief attempt to optimize costs without proven sustainability)

- Budgeting for DRG proportions (brief implementation attempt after a workshop)

- Systematic personnel development (uncoordinated individual measures without complete concept)

Inquire about results not only following a workshop or a workgroup but check the success and effectiveness one year later.

At this time often no one can remember the workshop and the results have been forgotten. However, this has gone unnoticed since the economic situation has improved thanks to happy circumstances and there is no longer pressure to act (no longer a feeling of malaise in the organization). Finalized results and agreed upon strategies that are forgotten without consequence are a poor condition for future developments.

In the existing structures, the resources of a hospital are often sufficient for selective measures (workshop, seminar series possibly with speakers from outside the hospital). However, sustainability is only ensured by integration in a long-term concept with continuous monitoring and refreshing and a personal responsibility for results. Optimization of processes and structures must be implemented in a timely fashion in "good" times (significant organizational preparations) (problem: money but no motivation) because in "bad" times resources are not available for this (problem: motivation but no money).

\section{Knowledge and ideas from 25 years of management experience \\ $\boldsymbol{\nabla}$}

Clarify your desire, ability and permission before beginning a task!

Framework conditions are often not sufficiently defined and scrutinized prior to duties and projects being assumed by management because these may not even be clear to the employer. Workshops and workgroups are then supposed to provide the solution.

Externally moderated workshops rarely shed light on strategic darkness.

Workshops are a (useful) part of operations but are not strategic. Without clear specification of the framework conditions and sufficient allocation of one's own time and qualified employees, successful project work is not possible ( $\bullet$ Fig. 2). Project work also requires a learning and practice phase on the part of future project managers. Successful project managers must have methodological, professional, and personal authority ("maturity"). Only in this way can those involved in project work come to trust in the success of the project. Experienced project managers have warning lights that go off well in advance in the case of potential risks. It might then be necessary to first clarify personal feelings in time-intensive personal conversations but this can only be done by experienced project managers with authority.

Even in the case of management, it is better to refuse a task than to proceed with implementation that can be expected to fail.

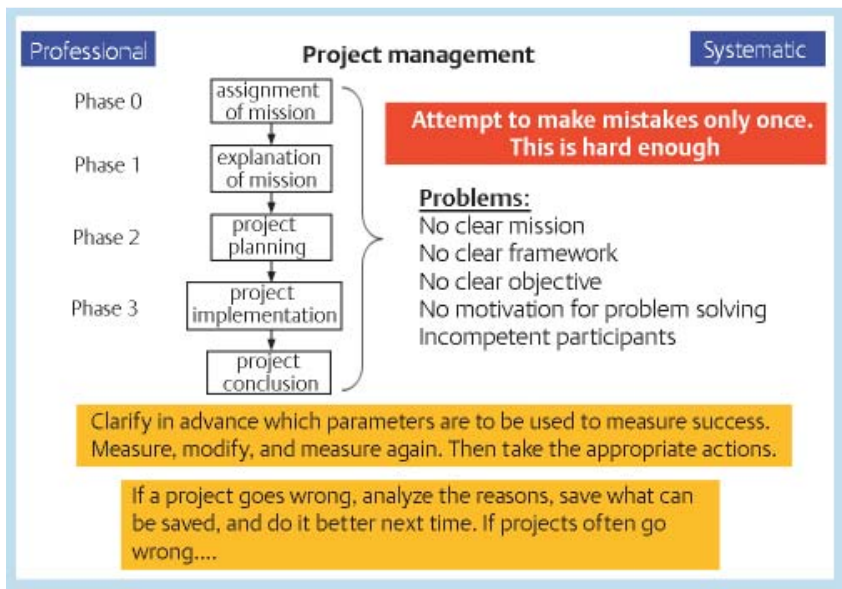

Fig. 2 Problems and risks in project management. 
In bad organizations "say yes and do nothing - it will be forgotten" is still an acceptable formula but this is not possible in good organizations. "Unwilling" participants often also attempt to quickly dramatically increase the degree of complexity to make the project task impossible. In this case only a consistent partly authoritarian limitation to the main issues (simplification) by an experienced project manager will help. The following presents experiences and tips from 25 years of management experience for discussion.

- Meet employees where they are (mentally) not where they should be.

- Do not overestimate existing social and management competence.

- Factor in the individual egotism of participants - what am I going to get out of it!

- Do not depend on the successful circulation of information. That only works for gossip and scandals!

- Without systematic repetition (practice) and regular monitoring, everything is quickly forgotten. In the case of insufficient resources (processes, structures, people), do not even start!

- Take time for personal conversations!

- Establish a positive climate of change before a workshop. Attempt to avoid "clear" losers in situations of conflict. Saving face is often the most difficult part of the task but avoids old scores and enemies.

- Never make important decisions spontaneously (always think it over for at least one night)!

- Check the quality of information before determining consequences and making decisions!

- Assess the significance and effects of a problem at the beginning. Determine the importance of a problem. Do not focus on rare organizational problems (look at the statistics first - Pareto Principle)! Then systematically resolve or ignore the problem.

- Don't personally handle every problem!

- Delegate and monitor - but remember that you ultimately remain responsible.

- Forget nothing (use IT or leave a note on your desk)!

- Do not form workgroups based on your own strategic and operational helplessness. Talk to each participant in advance (in private) and assure yourself of each participant's competence and motivation.

- At the start formulate clear nonnegotiable objectives and framework conditions in writing.

- Make sure your surroundings are also organized! (Cluttered desk $=$ cluttered mind $!)$

Managers are responsible for the outward appearance of the department and employees! Quality must be made visible by a corresponding environment.

- A key factor of an organization is a visually appealing front desk that is staffed by highly qualified staff and can be readily reached - this creates a good atmosphere prior to diagnosis/treatment and avoids complaints and legal conflicts.

- Exemplify what you demand of others!

A typical situation in the optimization of processes in hospitals and practices is as follows:

Employees are asked if they want to participate in a workgroup or a workshop. Everyone knows that this work is re- quired in addition to the daily workload - otherwise no one would be available for the daily routine. The answer is then: Not possible with my current workload - maybe later. If the employee is selected anyway, he/she tries to "survive" the workgroup or workshop by minimizing the effort or to bring about failure by quickly increasing the degree of complexity. The development potential of the organization is particularly limited when these employees are also senior management.

This is reminiscent of the following story:

A hiker asks a lumberjack in the woods for directions The lumberjack says that he is too busy to help. The hiker then asks the lumberjack why he doesn't sharpen his ax. The lumberjack responds that he has too much work to be able to sharpen his ax.

(Author unknown).

\section{Author comment}

This article is intended to encourage critical reflection of structures and roles in the organization of hospitals and practices. To a small degree this paper is a reflection of personal experiences at the Krankenhaus der Barmherzigen Brüder but is largely based on personal experiences gained at numerous management conventions and management training seminars, from providing consulting services to external hospitals and practices, from a regular exchange of experiences with corporate consultants, from reader reactions to my books and publications, and from frequent personal calls for help from head physicians and physicians. The content of this article will apply to some successful hospitals and private practices only in part or not at all. It is the goal of this paper to increase that proportion.

\section{Additional literature}

$\nabla$

H. P.Busch: Prozessoptimierung im Krankenhaus - Behandlungsabläufe im Überangebot bildgebender Untersuchungsmethoden. Arzt und Krankenhaus 2012 (2)

H.P.Busch: Wirtschaftlichkeitsreserven im Krankenhaus Eine kritische Analyse der Prozesse, Strukturen und Personen. Arzt und Krankenhaus 2012 (6)

H.P.Busch: Zwischen Qualität und Wirtschaftlichkeit. Arzt und Krankenhaus 2012 (11)

H.P.Busch: Imaging Center - Optimierung der diagnostischen Bildgebung im DRG Zeitalter. RÖFO; 2013 (184)

H.P.Busch, K.Galler, M.Dürr. Mit Syntegration Komplexität managen - Ein Weg, wie Krankenhäuser ihre Funktion nachhaltig erfüllen können. Das Krankenhaus 3, 2013

H.P.Busch: Managmenthandbuch für Radiologen. Thieme Verlag 2008

H.P.Busch: Managementhandbuch für Chefärzte. Thieme Verlag 2013 